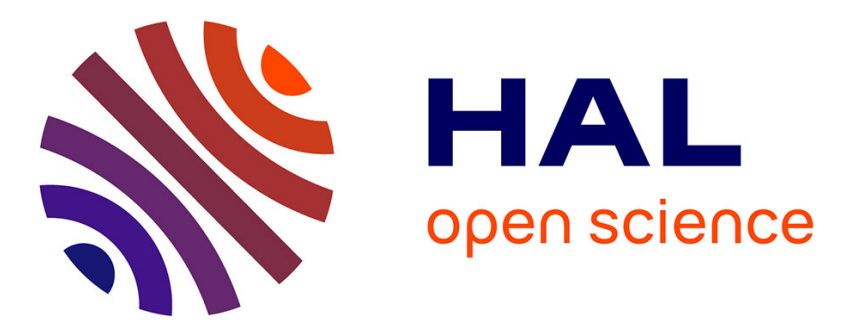

\title{
Modelling and acoustic monitoring of grout propagation in sands
}

Nadia Saiyouri, Ludovic Jason, Olivier Chupin, Pierre-Yves Hicher

\section{To cite this version:}

Nadia Saiyouri, Ludovic Jason, Olivier Chupin, Pierre-Yves Hicher. Modelling and acoustic monitoring of grout propagation in sands. Proceedings of the Institution of Civil Engineers - Ground Improvement, 2008, 161, pp.143-152. 10.1680/grim.2008.161.3.143 . hal-01529731

\section{HAL Id: hal-01529731 \\ https://hal.science/hal-01529731}

Submitted on 31 May 2017

HAL is a multi-disciplinary open access archive for the deposit and dissemination of scientific research documents, whether they are published or not. The documents may come from teaching and research institutions in France or abroad, or from public or private research centers.
L'archive ouverte pluridisciplinaire HAL, est destinée au dépôt et à la diffusion de documents scientifiques de niveau recherche, publiés ou non, émanant des établissements d'enseignement et de recherche français ou étrangers, des laboratoires publics ou privés. 


\title{
Modelling and acoustic monitoring of grout propagation in sands
}

\author{
N. Saiyouri, L. Jason, O. Chupin and P. Y. Hicher
}

Grouting is generally used for ground reinforcement or for reducing soil permeability. However, choosing grouting parameters or predicting improvements is at present rather empirical. A numerical approach may therefore enable grouting to be more efficient. The purpose of this paper is to model the evolution, in time and space, of two major variables: grout concentration and fluid pressure in grouted soil. After a brief description of a first tried diffusive model, this study aims to describe the performance of a software program, Athos. This program was initially developed for the oil industry and uses a piston model. Results are given in one- and three-dimensional approaches. They underline a rapid evolution of concentration from groutsaturated zones to non-saturated zones. The evolution of pressure depending on this degree of saturation is also highlighted. The second part of the paper compares the numerical model with a series of experiments carried out on grouted sand columns and in saturated sand tanks. In the latter tests, the grout is injected into the sand using a sleeved grout pipe, and the progress of grout propagation in the soil is monitored by acoustic emission (AE). This comparison shows the validity of the chosen model. The permeation distance detected by AE is compared with that predicted by simple grout propagation models.

\section{NOTATION}

C grout concentration

$\frac{C_{u}}{\bar{D}} \quad$ coefficient of uniformity

$\overline{\bar{D}} \quad$ diffusion second-order tensor

g acceleration due to gravity

$K \quad$ intrinsic permeability

$K_{\mathrm{h}}, K_{\mathrm{V}}$ horizontal and vertical permeabilities

$K_{\mathrm{rw}} \quad$ relative permeability of water $(=1)$

$k_{x}, k_{y}$ permeabilities in $x$ and $y$ directions

$n \quad$ porosity

$\boldsymbol{P}$ fluid pressure

$\boldsymbol{p}_{\text {atm }}$ atmospheric pressure

$\boldsymbol{p}_{\text {i }} \quad$ initial pore pressure

$q$ grout pumping rate

$R \quad$ mobility reduction factor for water phase

$r \quad$ extent of injection bulb

$S_{\alpha} \quad$ saturation of $\alpha$-phase

$S_{\mathrm{w}} \quad$ degree of saturation

$t \quad$ time $u$

$V_{\mathrm{w}} \quad$ Darcy's velocity of fluid

$\boldsymbol{v}_{\mathrm{fl}} \quad$ macroscopic velocity of fluid phase

$\boldsymbol{v}_{\mathrm{s}}$ macroscopic velocity of solid phase

$X \quad$ molar fraction of polymer

$\beta_{\mathrm{w}} \quad$ water molar density

$\gamma_{\mathrm{s}} \quad$ specific weight

$\boldsymbol{\mu}_{\mathrm{fl}} \quad$ fluid dynamic viscosity

$\boldsymbol{\mu}_{\mathrm{w}} \quad$ viscosity of water

$\rho_{\mathrm{fl}} \quad$ density of fluid phase

$\rho_{\mathrm{s}} \quad$ density of solid grains

$\rho_{\mathrm{w}} \quad$ water density

$\boldsymbol{\sigma}_{i j}^{\prime} \quad$ Terzaghi's effective stress

\section{INTRODUCTION}

Grouting is an old technique, used to decrease the permeability of soil, or for ground reinforcement. It consists in injecting grout into the soil that needs to be treated. ${ }^{1}$ The choice of grouting parameters or the prediction of the improvements remains rather empirical. Propagation mechanisms for cement grout must be investigated for a more efficient treatment. Injection of gravels and sands is only carried out easily by using a sleeved grout pipe fixed in the soil with a casing grout. ${ }^{2}$ In this case the grout propagates inside the soil through cracks that appear during fracturing of the casing grout. This equipment was also used in the tank experiments presented by Chupin et $a .^{3}$ Two parameters are of interest: the distribution in time and space of the grout concentration from the point of injection, and the fluid pressure. However, the prediction of these evolutions is empirical, and the recent replacement of chemical grouts by micro cement grouts, for environmental reasons, makes the problem still harder. ${ }^{4}$ Numerical models are therefore being developed, ${ }^{5}$ in an effort to improve knowledge of the process and eventually to decrease industrial costs.

In this paper, two models are proposed to solve the problem. The validation of each one is studied with experimental results. The first model is based on a diffusive approach, and uses transport and conservation equations. ${ }^{6,7}$ Several authors have proposed similar studies, which can be applied to the case of injection. ${ }^{8-11}$ This approach needs to take complex phenomena into account in order to achieve good results. ${ }^{12}$ The studies by Choquet ${ }^{13}$ and Nithiarasu et al. ${ }^{14}$ offer some interesting complements to this work. 
Given the porosity $n$, the macroscopic velocities of the fluid and solid phases ( $\boldsymbol{v}_{\mathrm{fl}}$ and $\boldsymbol{v}_{\mathrm{s}}$ respectively), the densities of the fluid phase and the solid grains ( $\rho_{\mathrm{fl}}$ and $\rho_{\mathrm{s}}$ ), the grout concentration $C$, time $t$, and the diffusion second-order tensor $\overline{\bar{D}}$ (see Bear's model ${ }^{15,16}$ ), we have the following equations. For the solid phase

$$
\frac{\partial(1-n) \rho_{\mathrm{s}}}{\partial t}+\nabla\left[(1-n) \rho_{\mathrm{s}} \boldsymbol{v}_{\mathrm{s}}\right]=0
$$

For the fluid phase

2

$$
\frac{\partial\left(n \rho_{\mathrm{fl}}\right)}{\partial t}+\nabla\left(n \rho_{\mathrm{fl}} \boldsymbol{v}_{\mathrm{fl}}\right)=0
$$

For the miscible grout$$
3
$$

$$
\frac{\partial(n C)}{\partial t}+\nabla\left(-n \boldsymbol{D}_{i j} \vec{\nabla} C\right)+\nabla\left(n C \boldsymbol{v}_{\mathrm{fl}}\right)=0
$$

Darcy's law and the general momentum equilibrium equation are added to give

$$
n\left(\boldsymbol{v}_{\mathrm{fl}}-\boldsymbol{v}_{\mathrm{s}}\right)=-\frac{K}{\boldsymbol{\mu}_{\mathrm{fl}}}\left(\nabla \boldsymbol{P}-\rho_{\mathrm{fl}} \boldsymbol{g}\right)
$$

$$
\nabla\left(\boldsymbol{\sigma}_{i j}^{\prime}-\boldsymbol{P} \delta_{i j}\right)+\rho \boldsymbol{g}=0
$$

where $K$ is the intrinsic permeability, $\boldsymbol{\mu}_{\mathrm{fl}}$ is the fluid dynamic viscosity, $\boldsymbol{P}$ is the fluid pressure, $\boldsymbol{\sigma}_{i j}^{\prime}$ is Terzaghi's effective stress, $\boldsymbol{g}$ is the acceleration due to gravity, and $\rho$ is defined as

\section{6}

$$
\rho=(1-n) \rho_{\mathrm{s}}+n \rho_{\mathrm{fl}}
$$

The second modelling possibility concerns the use of the piston model. This model states that grout displacement occurs only as a result of the pressure imposed at the injection point. It is necessary to adapt the Athos software used in the oil industry to model polymer propagation in oil production wells, ${ }^{17}$ by adjusting the equations to suit the grouting problem. The results, in both one and three dimensions, show real differences from the simple diffusive model. The results seem to fit, at least qualitatively, in situ observations of the time needed for full saturation, or the position of the saturation front.

To obtain a quantitative validation, the results given by Athos are compared with a series of experiments carried out on grouted sand columns and tanks. The variety of sand and grout characteristics (granulometry and density) provides a large number of samples, and therefore makes it possible to propose a range of applications for the model.

\section{MATERIALS AND METHODS}

First, a set of experiments carried out for FNTP ${ }^{18}$ on sand columns are described. Then details of experiments using cylindrical tanks $50 \mathrm{~cm}$ in diameter are given. For the sand columns, the sand and grout characteristics are given in Tables 1 and 2 respectively. For the tank experiments, the materials used are Loire or Fontainebleau sand samples, the properties of which are given in Table 3.

\section{I. One-dimensional device}

The experimental device is shown in Fig. 1(a). ${ }^{19}$ The samples are sand columns, $1 \mathrm{~m}$ high and $0.08 \mathrm{~m}$ in diameter. The grouted cell is instrumented with five pressure transducers placed at regular intervals along the column (see Fig. 1(b)) to follow the evolution of pressure in time and space during grouting. A sixth transducer is located near the pump used for the injection.

The grouting is performed with a constant pumping rate $(q=$ $2 \cdot 5 \mathrm{~cm}^{3} / \mathrm{s}$ ). Table 4 presents some characteristics of the column used for the simulation work.

\subsection{Tank injection procedure}

The injection tests are performed in small tanks, $1 \cdot 70 \mathrm{~m}$ high and $0.5 \mathrm{~m}$ in diameter, filled with Loire or Fontainebleau sand. ${ }^{20}$ The cement grout is injected into the sand using a sleeved grout pipe. ${ }^{21,22}$ During the injection, the pumping pressure is recorded. The grout propagation is monitored by acoustic emission (AE). The AE instrumentation is composed of wave guides coupled with transducers. The wave guides are

\begin{tabular}{|lccc|}
\hline Sand & $D_{60} / D_{10}$ & $D_{50}: \mathrm{mm}$ & $D_{15}: \mathrm{mm}$ \\
\hline Fontainebleau & 1.91 & 0.19 & 0.11 \\
FI5 & 1.81 & 0.20 & 0.13 \\
F25 & 1.79 & 0.29 & 0.19 \\
F35 & 1.66 & 0.51 & 0.40 \\
\multicolumn{4}{l}{ Table I. Characteristics of sands } \\
\end{tabular}

\begin{tabular}{|lcrc|}
\hline Cement & $D_{60} / D_{10}$ & $D_{50}: \mu \mathrm{m}$ & $D_{85}: \mu \mathrm{m}$ \\
\hline Average & 4.2 & 10.30 & 19.9 \\
Fine & 4.3 & 4.60 & 8.8 \\
Ultra-fine & 5.0 & 1.32 & 3.6 \\
\multicolumn{4}{l}{} \\
Table 2. Characteristics of cements
\end{tabular}

\begin{tabular}{|lc|}
\hline Property & Value \\
\hline & \\
Specific weight, $\gamma_{\mathrm{s}}: \mathrm{kN} / \mathrm{m}^{3}$ & $26 \cdot 2$ \\
Minimum unit weight, $\gamma_{\min }: \mathrm{kN} / \mathrm{m}^{3}$ & $15 \cdot 1$ \\
Maximum unit weight, $\gamma_{\max }: \mathrm{kN} / \mathrm{m}^{3}$ & $18 \cdot 5$ \\
Coefficient of uniformity, $C_{\mathrm{u}}$ & $3 \cdot 5$ \\
Mean grain size, $D_{50}: \mu \mathrm{m}$ & 520 \\
Porosity of sample & $0 \cdot 316$ \\
Weight of sample: $\mathrm{kg}$ & 568 \\
Height of sample: $\mathrm{m}$ & 1.495 \\
Relative density of sample: \% & 83 \\
& \\
Table 3. Material properties & \\
\hline
\end{tabular}




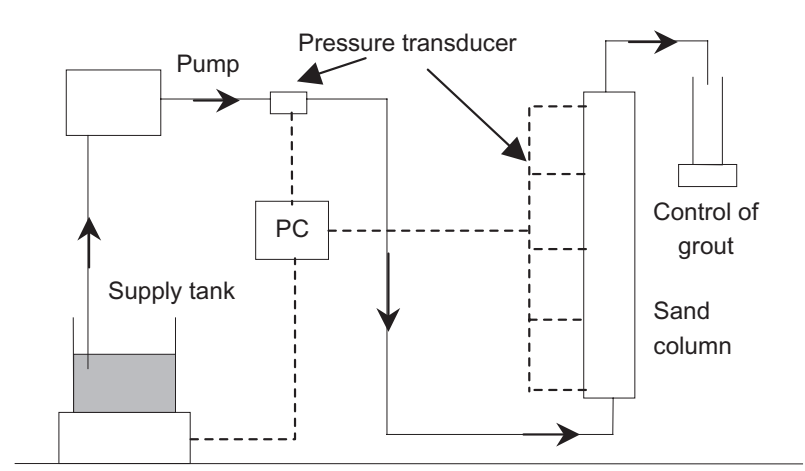

(a)

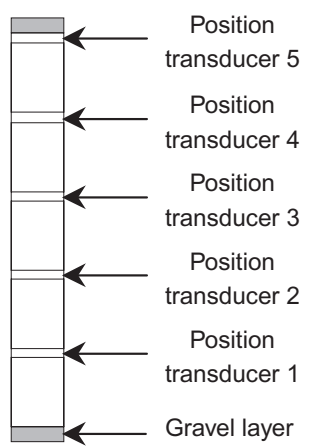

(b)

Fig. I. Experimental device for: (a) laboratory injection; (b) sand column

\begin{tabular}{|lc|}
\hline Property & Value \\
\hline Young's modulus: $\mathrm{MPa}$ & 13 \\
Porosity & 0.3 \\
Skeleton density: $\mathrm{kg} / \mathrm{m}^{-3}$ & 1950 \\
Fluid viscosity: Pa/s & $0.00 \mathrm{II}$ \\
Compressibility coefficient: $\mathrm{Pa}^{-1}$ & $3.4 \times 10^{-8}$ \\
Diffusion coefficient: $\mathrm{m}^{2} / \mathrm{s}$ & $2 \times 10^{-10}$ \\
Fluid density: $\mathrm{kg} / \mathrm{m}^{3}$ & 1000 \\
Intrinsic permeability: $\mathrm{m}^{2}$ & $1.57 \times 10^{-11} \mathrm{~m}^{2}$ \\
& \\
Table 4. Material properties in column & \\
\hline
\end{tabular}

driven vertically into the sand sample (see Fig. 2). An increase of the acoustic activity is observed when the injected fluid reaches the wave guide. The injection is performed at a constant pumping rate $\left(q_{\mathrm{imp}}=2.78 \times 10^{-5} \mathrm{~m}^{3} / \mathrm{s}\right)$. The grout is injected for $720 \mathrm{~s}$.

\section{PISTON MODEL}

The model presented below is implemented in the Athos program, used in the oil industry to model multiphase flows (water, air, oil, polymer) in reservoirs. Athos uses a pre- and post-processor, Simview, which can simulate a complex geometry (3D, injection or production wells), can deal with numerous thermodynamical and petrophysical parameters (porosity, anisotropy of permeabilities) and can propose different models (chemical, polymer or tracer). To adapt the software to our problem, the grout is assimilated to a polymer component in the liquid phase. The model is based on mass conservation equations for the $\alpha$-phase and for the water components. The phase velocities are expressed by Darcy's law. A non-deformable porous medium is considered. The problem is discretised in time by finite differences and discretised in space using the finite-volume method.

The software deals with the following three equations.

For the fluid phase (conservation)

7

$$
\frac{\partial}{\partial t}\left(n \beta_{\mathrm{w}} S_{\mathrm{w}}\right)+\operatorname{div}\left(\beta_{\mathrm{w}} \boldsymbol{V}_{\mathrm{w}}\right)=0
$$

For the grout (assimilated as a polymer)

$$
\frac{\partial}{\partial t}\left(n \beta_{\mathrm{w}} S_{\mathrm{w}} X\right)+\operatorname{div}\left(\beta_{\mathrm{w}} X \boldsymbol{V}_{\mathrm{w}}\right)=0
$$

Darcy's law

$$
\boldsymbol{V}_{\mathrm{w}}=X-K \frac{K_{\mathrm{rw}}}{R \boldsymbol{\mu}_{\mathrm{w}}}\left[\operatorname{grad}(\boldsymbol{P})-\rho_{\mathrm{w}} \boldsymbol{g}\right]
$$

where $n$ is the porosity of the porous material, $\beta_{\mathrm{w}}$ is the water molar density, $S_{\alpha}$ is the saturation of the $\alpha$-phase, and $\boldsymbol{\mu}_{\mathrm{w}}$ denotes the water phase viscosity. $R$ is the mobility reduction factor for the water phase due to polymer effects that modify the water phase properties; it is used to enable an evolution of $K$ or $\boldsymbol{\mu}_{\mathrm{w}}$ during grouting. To model injection tests, only the wetting phase is needed, so that the degree of saturation, $S_{\mathrm{w}}$, is here taken equal to $1 . V_{\mathrm{w}}$ is Darcy's velocity of the fluid, $X$ the molar fraction of the polymer, $K$ is the intrinsic permeability, $K_{\mathrm{rw}}$ is the relative permeability of water (equal to 1 ), $\boldsymbol{P}$ is the fluid pressure, $\rho_{\mathrm{w}}$ is the water density, and $\boldsymbol{g}$ is the acceleration due to gravity.

These equations are then discretised in time and space using finite differences. With the hypothesis that, for a given time step and for the same cell of the discretisation, each unknown is constant, we obtain a system of two equations with two unknowns ( $X$ and $\boldsymbol{P}$ ). Note that this software does not give results for the mechanical aspects.

\section{RESULTS AND EXPERIMENTAL VALIDATION}

\section{I. Validation results for columns}

This section aims to confirm the numerical results by comparing them with experiments, and deduce which of the two models (diffusive or piston) gives the best results.

4.1.1. One-dimensional simulation modelled by simple diffusive approach. Three equations with three unknowns ( $\boldsymbol{P}, C$, and $u$ the solid displacement expressed with an elastic hypothesis) are finally obtained. Discretising in time (finite differences) and space (Galerkin finite-element method), the equation system is solved in a one-dimensional approach. ${ }^{23}$ Fig. 3 shows the boundary and initial conditions. The parameters and geometry in terms of normalised concentration $[C(x) / C(0)]$ are shown in Tables 4 and 5. 


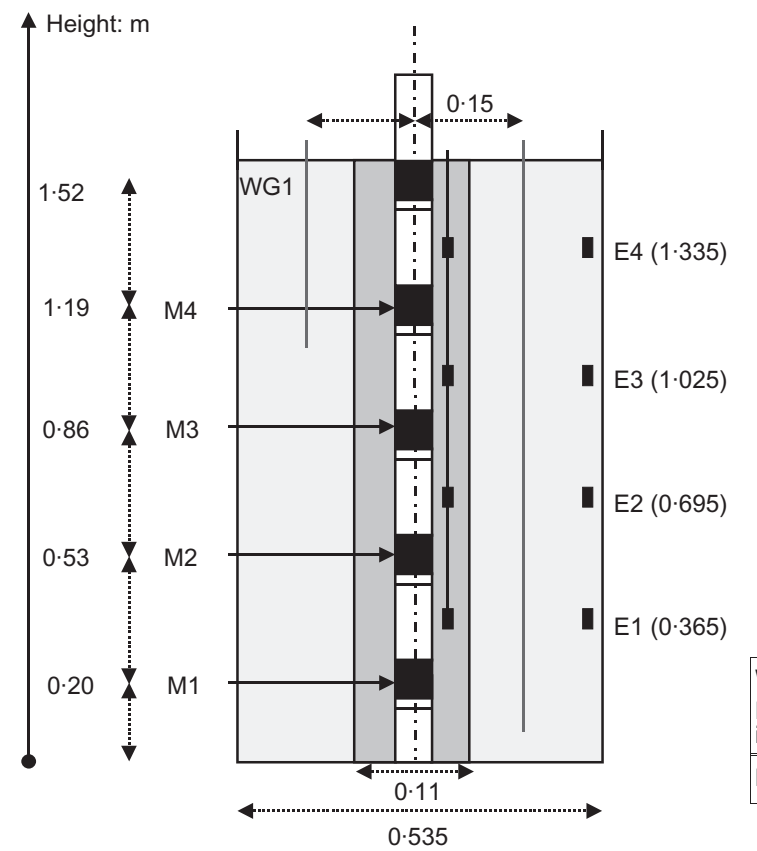

Fig. 2. Layout of sand tank and instrumentation

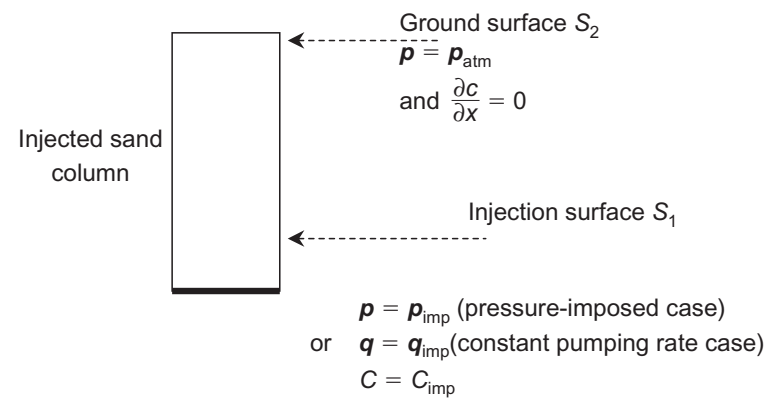

Fig. 3. Boundary and initial conditions for grouting test. Initial conditions are $c(x, y, z, t=0)=0, \boldsymbol{p}(x, y, z, t=0)=\boldsymbol{p}_{\mathrm{i}}(\mathrm{z})$. $\boldsymbol{p}_{\mathrm{i}}=$ initial pore pressure; $\boldsymbol{p}_{\mathrm{atm}}=$ atmospheric pressure

Figure 4 presents the concentration results of the simulation. It can be seen that the shape of the curve is acceptable. The results are coherent qualitatively, but not quantitatively. After a grouting time of $20 \mathrm{~min}$ the column is not yet saturated in grout, and the decreasing rate of evolution tends to show that full saturation will never be reached. This is the first weak point, compared with experiments. Moreover, the transition from the grout-saturated zone to the non-saturated zone (TZ in Fig. 4) is large, which is contrary to experimental observations. These two points emphasise that the model does not describe well the phenomena that actually happen in the injection

\begin{tabular}{|lc|}
\hline Column height: $\mathrm{m}$ & 2 \\
Element length, $\Delta x: \mathrm{m}$ & $0 \cdot 05$ \\
Time step, $\Delta t: \mathrm{s}$ & 40 \\
Time of simulation: min & 20 \\
& \\
Table 5. Simulated geometry & \\
\hline
\end{tabular}

propagation, which does not seem to follow a diffusion mechanism. Two solutions are possible: to complete the present model, or to change it radically. The second option is chosen in the following section.

\subsubsection{One-dimensional} simulation with Athos model (piston approach). In this section, the tested geometry is a sand column modelled with 400 cells in the $z$ direction (2 $\mathrm{m}$ high) and one cell in the transverse direction. The characteristics of the injected sand or balls of glass (BV) column are given in

Table 6.

The principle of the numerical simulation is to introduce grout at the bottom of the column and achieve saturation when the grout reaches the top of the $2 \mathrm{~m}$ height. The $(x, y)$ cell is assumed to be thin enough to consider a onedimensional approach for the Athos software. The permeabilities in the $x$ and $y$ directions $\left(k_{x}\right.$ and $k_{y}$ ) are taken as equal to zero. The physical parameters are those given in Table 4 ; the evolution of fluid viscosity is added, so that $\boldsymbol{\mu}$ is linearly dependent on grout concentration, with $\boldsymbol{\mu}=1 \cdot 1 \times 10^{-3} \mathrm{~Pa} / \mathrm{s}$ when $c=0$, and $\boldsymbol{\mu}=2 \cdot 8 \times 10^{-3} \mathrm{~Pa} / \mathrm{s}$ when $\left.c=c_{\max }\right)$. The simulation is for a constant pumping rate $\left(q=6 \mathrm{~cm}^{3} / \mathrm{s}\right)$. The results are given for different times $(t=40-1200 \mathrm{~s})$ in Fig. 5 .

4.1.3. Three-dimensional simulation for piston model. Athos is essentially used to generate three-dimensional geometry. The goal of this section is to model a real column of sand whose dimensions are $0.1 \mathrm{~m} \times 0.1 \mathrm{~m} \times 2 \mathrm{~m}$ (current laboratory experiments). The column is defined as a parallelepiped with five cells in the $x$ and $y$ directions $(\Delta x=\Delta y=0.02 \mathrm{~m})$ and 200 cells in the $z$ direction $(\Delta z=0 \cdot 01 \mathrm{~m})$.

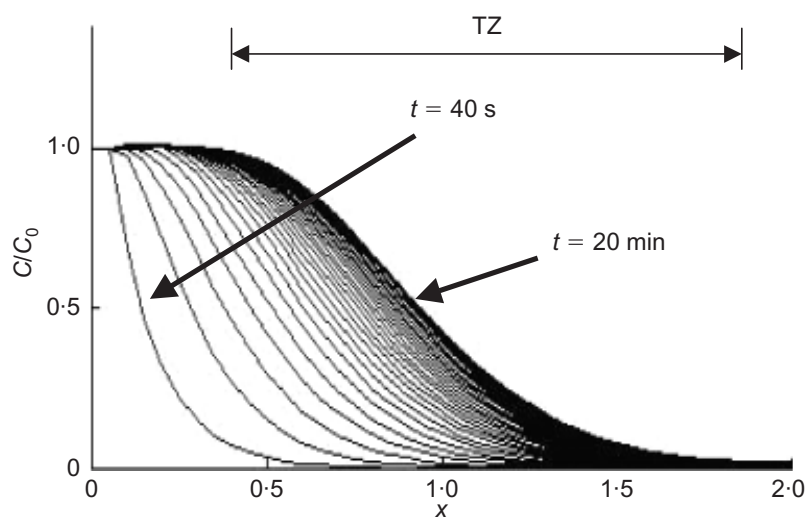

Fig. 4. Simple diffusive model results in one-dimensional configuration 

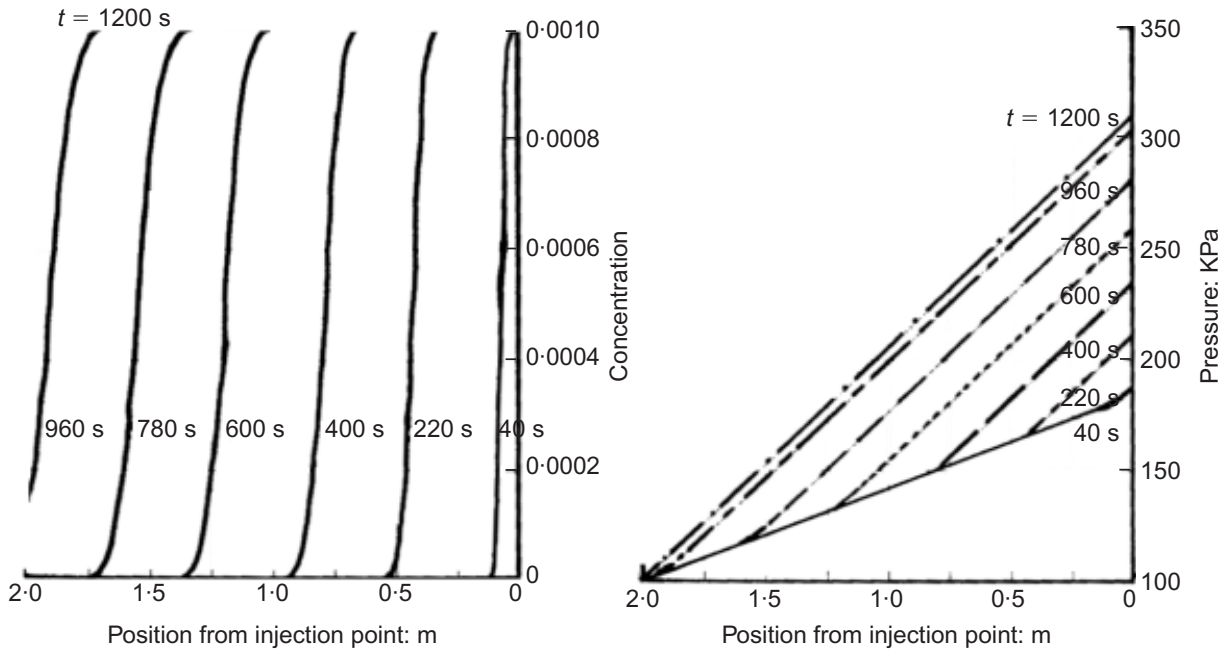

Fig. 5. (a) Concentration and (b) pressure results of Athos simulations: I

transition zone (TZ in Fig. 4) is also thin. This result has already been observed in the one-dimensional simulation (see section 4.1.2), and is confirmed for the threedimensional case.

Finally, it can be shown that, for the imposed pressure case, the pressure increases in grout-saturated zones and decreases in non-grouted zones. We can therefore assume that the transition over time from a nonsaturated state to a saturated one imposes a modification in the sense of pressure evolution. That is to say that, if pressure increases between

To ensure three-dimensional simulation, $k_{\mathrm{x}}$ and $k_{\mathrm{y}}$ values are needed. They are taken as equal to $k_{z}$ (isotropic case). The test will be an imposed pressure case with $\boldsymbol{P}_{\text {inj }}=250 \mathrm{kPa}$ and with the parameters defined in Table 4. The results are given in Fig. 6 (cross figures in $z$ direction). Full grout saturation is obtained at a time of $1000 \mathrm{~s}$.

For a given $z$, pressure and concentration are constant in the $5 \times 5$ cells in $(x, y)$ plan. This observation can be explained by the conditions chosen for the simulation, and by the isotropy of the test. It is indeed assumed that there are 25 injection points at the bottom of the column (boundary conditions represented as white circles in the Figs 6(a) \&t 6(b)). This makes it possible to model, as precisely as possible, a real case where the injection is made across all the bottom. This condition creates a symmetry of the simulation, which may lead to a symmetry of results.

The part located between the grout-saturated zone $\left(c=c_{\max }\right)$ and the non-grouted zone $(c=0)$ is clearly marked. The $t$ and $t+\Delta t$, for a given $z$, the considered zone is or was saturated during or before this time. If it decreases, the zone does not contain any grout. Differing behaviour is therefore observed, depending on the degree of grout saturation.

Figure 7 shows the numerical and experimental results of a second test, for which the characteristics are sand type F15, dry volumetric density $1.49 \mathrm{~g} / \mathrm{cm}^{3}$, fine cement $\mathrm{CE}=20 \%$, grout viscosity $1.5 \times 10^{-3} \mathrm{~Pa} / \mathrm{s}$, and initial sand permeability $1.2 \times$ $10^{-11} \mathrm{~m}^{2}$.

In terms of concentrations, the experimental saturation is obtained for $t=800 \mathrm{~s}$. Athos provides an acceptable time of 780 s. It models a clear boundary (see above) between the grout-saturated zone and the non-grouted zone (thin transition). It uses a piston model, in which grout progresses owing to pressure by filling soil voids and replacing water. Experiments confirm this approach. One can indeed notice in the column a 'grey' zone saturated with grout, a non-grouted zone $(c=0)$, and a very thin intermediate zone. As

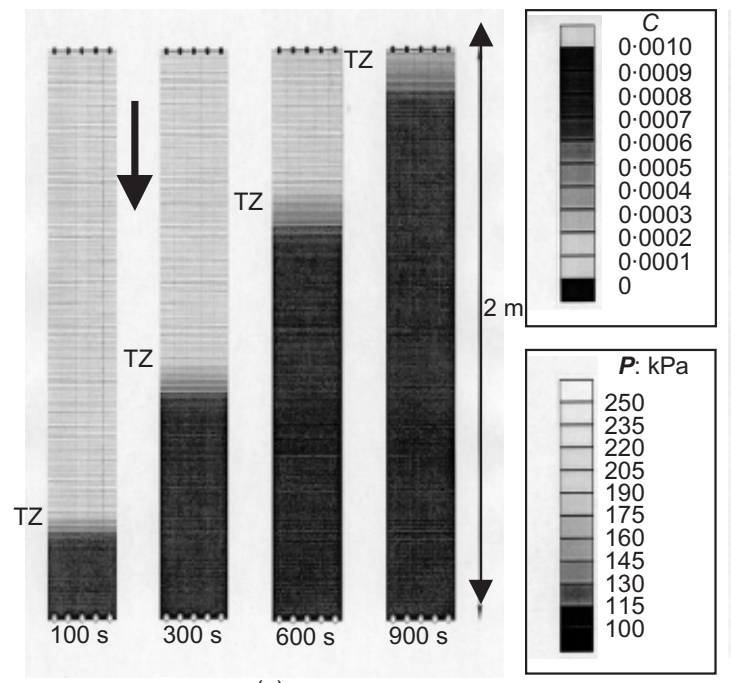

(a)

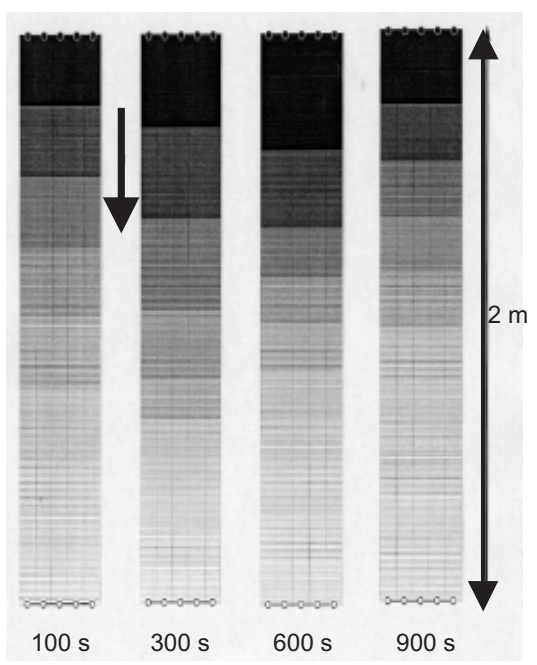

(b) far as concentrations are concerned, the model seems to fit the experiment both qualitatively and quantitatively. In terms of pressure, Athos provides values in accordance with experiments. Experimental results are given here for each transducer from the time when the grout arrives at the corresponding depth. Some other tests show a stationary state of pressure (i.e. $\boldsymbol{p}$ remains constant) before saturation (i.e. before the presence of grout). This observation was noticed with Athos (see section 4.1.2)

Fig. 6. (a) Concentrations and (b) pressures in three-dimensional and column simulation 


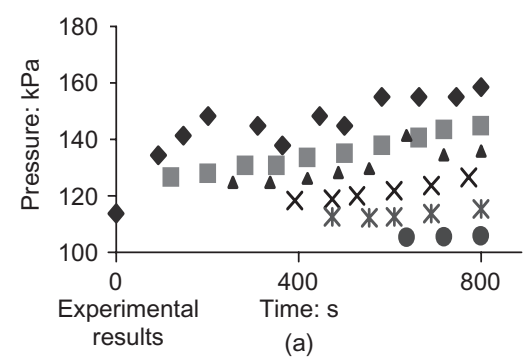

\begin{tabular}{|l|}
\hline Pump transducer \\
Transducer 1 \\
X Transducer 2 \\
* Transducer 3 \\
Transducer 4 \\
Transducer 5
\end{tabular}

Transducer 5

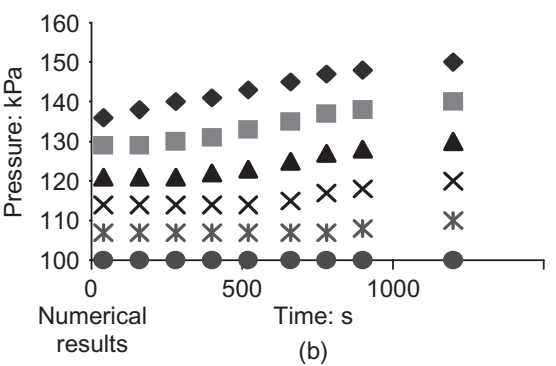

(b)

Fig. 7. (a) Experimental and (b) numerical results for 3D sand column grouting. Sand characteristics: FI5, dry volumetric density $1.49 \mathrm{~g} / \mathrm{cm}^{3}$. Cement: fine, C/E $20 \%$. Grout viscosity: $1.5 \times 10^{-3} \mathrm{~Pa} / \mathrm{s}$. Initial sand permeability: $1.2 \times 10^{-11} \mathrm{~m}^{2}$

Numerical simulations propose, wherever the transducer is located, a gradual evolution of pressure (linear evolution) from the time when the grout reaches its level. Experiments show more complex evolution in some cases. These differences may be explained, first, by the difficulty of measuring pressure in the column; second, by the nature of the model, which uses only continuous parameters and equations; and finally by the boundary conditions, which cannot be verified in experimental tests (for example, the experimental pressure at the top of the column is different from atmospheric pressure). It was therefore difficult to foresee a perfect correspondence between the numerical simulation and the experimental data.

\subsection{Experimental results for tank test}

4.2.1. Grout and water saturation. The saturation of the sand is obtained by injecting water (77.16 litres) through sleeve 2 (M2 in Fig. 2). During injection the decrease of the electrical resistance is successively measured by electrodes 1, 2 and 3 . After the saturation phase the height of the saturated sand in the tank is approximately $1.18 \mathrm{~m}$. The height of saturating water detected by resistivity measurements is compared with a theoretical height calculated using the volume of injected fluid, the porosity of the porous medium, and the sand section in a horizontal plane $\left(0 \cdot 210 \mathrm{~m}^{2}\right)$. The results are summarised in Table 7. The experimental detection is recorded before the theoretical front of the saturating water arrives at the various electrodes.
4.2.2. Acoustic emission results and their simulation for tanks. Figure 8 presents the experimental results for acoustic emission for waveguides 4 and 5 (Figs 8(a) and 8(b) respectively). The time at which the grout is assumed to reach the given point in the medium is indicated by an arrow. It corresponds to the beginning of the rise of the recorded points group. Moreover, a calculation has been made with Athos software. The medium is therefore assumed to be isotropic: that is, the horizontal and vertical permeabilities are equivalent. Fig. 9 shows the evolution of the normalised concentration profile with time and distance from the injection point. The $\mathrm{AE}$ detection is shown by the dotted lines. The whole concentration field is not available by AE; only the grout presence is detected when the grout concentration becomes non-zero at the waveguide location. Hence the model gives a good approximation of the radial distance of the grouted zone at $t=320 \mathrm{~s}$, since the numerical concentration at this time starts to increase. At $t=120 \mathrm{~s}$ the numerical concentration at

\begin{tabular}{|lrrrr|}
\hline & \multicolumn{4}{c|}{ Electrode } \\
\cline { 2 - 5 } & EI & E2 & E3 & \multicolumn{1}{c|}{ E4 } \\
\hline Electrode position: $m$ & 0.36 & 0.69 & 1.02 & 1.33 \\
Injected volume: I & 8.03 & 38.63 & 59.80 & 85.14 \\
Theoretical height: $m$ & 0.12 & 0.59 & 0.91 & 1.28 \\
& & & & \\
Table 7. Comparison between numerical and experimental \\
front position of injected fluid
\end{tabular}

\begin{tabular}{|lccccccc|}
\hline Sample & $\begin{array}{c}\text { Density } \\
\mathrm{g} / \mathrm{cm}^{3}\end{array}$ & Grout & C/E: \% & $\begin{array}{c}\text { Viscosity: } \\
10^{-3} \mathrm{~Pa} / \mathrm{s}\end{array}$ & $\begin{array}{c}\text { Permeability: } \\
10^{-11} \mathrm{~m}^{2}\end{array}$ & $\begin{array}{c}\text { Pump transducer } \\
\text { maximum experimental } \\
\text { pressure: } \mathrm{kPa}\end{array}$ & $\begin{array}{c}\text { Pump transducer } \\
\text { maximum numerical } \\
\text { pressure: } \mathrm{kPa}\end{array}$ \\
\hline FI5 & 1.62 & Fine & 20 & 1.5 & 1.1 & 280 & 154 \\
FI5 & 1.33 & Fine & 20 & 1.5 & 1.4 & 125 & 142 \\
FI5 & 1.49 & Fine & 20 & 1.5 & 1.2 & 150 & 150 \\
FI5 & 1.60 & Ultra-fine & 20 & 1.5 & 1.2 & 280 & 150 \\
F25 & 1.66 & Fine & 20 & 1.5 & 2.1 & 160 & 129 \\
F25 & 1.37 & Average & 20 & 2.8 & 2.4 & 150 & 145 \\
F25 & 1.63 & Fine & 5 & 1.1 & 2.1 & 175 & 120 \\
F35 & 1.65 & Average & 20 & 2.8 & 5.6 & 150 & 120 \\
F35 & 1.50 & Average & 20 & 2.8 & 5.7 & 130 & 120 \\
BV & 1.53 & Fine & 20 & 1.5 & 1.3 & 180 & 146 \\
BV & 1.65 & Fine & 20 & 1.5 & 1.2 & 300 & 150
\end{tabular}

Table 6. Maximum pump pressure comparison 


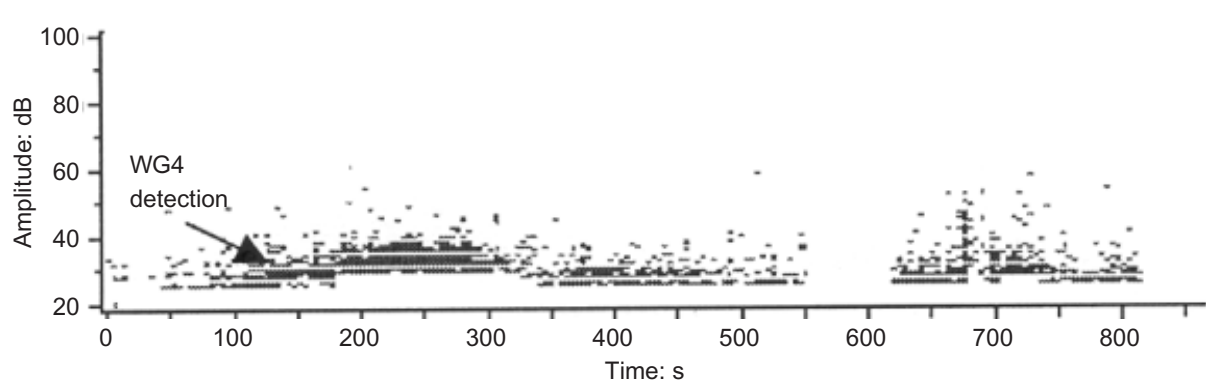

(a)

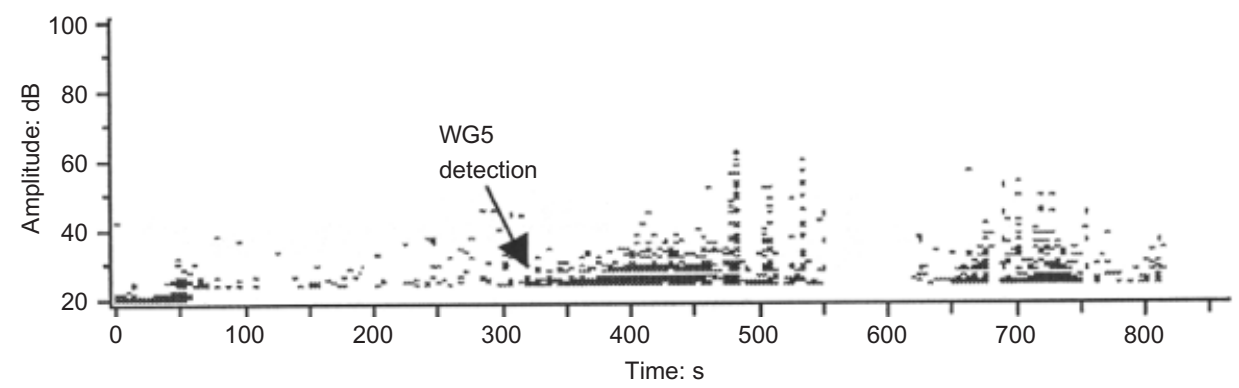

(b)

Fig. 8. Grout propagation monitored by acoustic emission: (a) waveguide 4; (b) waveguide 5

column (grout concentration equal to zero). Finally, the comparison can be extended to all of the tests carried out in this study. For reasons of convenience, Table 6 addresses only the pump transducer maximal pressure.

From this table, some conclusions can be obtained.

(a) Whatever the sand or grout characteristics (with some exceptions), the values of maximal pump pressure are reproduced rather well by Athos. The numerical model thus gives a good approximation of pressure evolution and values.

(b) The results given by Athos are particularly

$r=13 \mathrm{~cm}$ is nearly $0 \cdot 5$ when WG4 detects the presence of grout. The numerical model predicts a grouted radial distance slightly larger than that detected by $\mathrm{AE}$ at this point. This can probably be connected to the reading difficulty of the experimental results (group of dots on the graph)

\section{DISCUSSION}

\section{I. Model validation with column tests}

We first analyse the results of diffusive model calculations and compare them with the experiments with column injection tests. The concentration curves for $t=400 \mathrm{~s}$ in Fig. 5 can be schematised as illustrated in Fig. 10. They are ' $0-1$ ' functions defining grout-saturated zones $\left(c=c_{\max }\right.$ from the injection point to point 1 ), non-grouted zones ( $c=0$ from point 2 to the surface), and a thin transition zone (from point 2 to point 1 ). Obviously, the grout-saturated zone becomes larger with time. Full saturation is obtained here in a time of $960 \mathrm{~s}$.

In terms of pressure, all the curves (from Fig. 5) can be presented in the same manner as concentration, as schematised in Fig. 11. An increase is noticeable at the injection point. This evolution could have been predicted: to maintain a constant pumping rate, the applied pressure has to be higher (the grout is responsible for a 'resistant' effect). One can also observe an increase of pressure over time in the grout-saturated zones and a stationary state in the nongrouted zones. Taking into account the schema of concentrations presented above, the break in the pressure curves is always located between point 2 (last point with $c=$ 0 ) and point 1 (first point with $c=c_{\max }$ ). The first part of the curve (from the injection point to point 1) thus simulates pressure behaviour in grout-saturated zones, and the second part (from point 2 to the surface) simulates pressure behaviour in non-grouted zones (see Fig. 11). It is therefore possible to confirm the increase of pressure in groutsaturated sand and a non-evolution in the other part of the satisfying for coarse or loose sand. For F35 sand (with $\rho=$ $1.5 \mathrm{~g} / \mathrm{cm}^{3}$ ), F25 sand (with $\rho=1.37 \mathrm{~g} / \mathrm{cm}^{3}$ ) and F15 sand $\left(\rho=1.45 \mathrm{~g} / \mathrm{cm}^{3}\right)$, the differences between the numerical and experimental values are acceptable. For BV, it seems to be very difficult to reach satisfying conclusions.

These observations may be explained by some more complex phenomena, which are not taken into account in the Athos simple simulation but which have a greater influence on fine, dense sands.

\subsection{Model validation with tank tests}

This section addresses the results for tank injection with electrode instrumentation. The results shown in Table 7 show good agreement between those obtained by experiment and by calculation. The slight difference observed in the first value may have various causes, as follows.

(a) The capillarity effect is responsible for a wetting particle front detected by the electrodes.

(b) The injection process causes sand particles to move and breaks the homogeneity of the sample.

(c) The accessible porosity is not equal to the effective one, which distorts the theoretical results.

(d) The electrode positions are known to within $3 \mathrm{~cm}$.

The phenomena described above may have simultaneous effects.

\subsection{Dimensions of the grouted zone}

The calculated concentrations have to be validated by experimental concentrations deduced from the dimensions of the injection bulb (real injected zone). This bulb size is estimated in two configurations (Fig. 12): spherical (equation (10)) and ellipsoidal (equation (11)). These configurations consider respectively isotropic and anisotropic soils. 


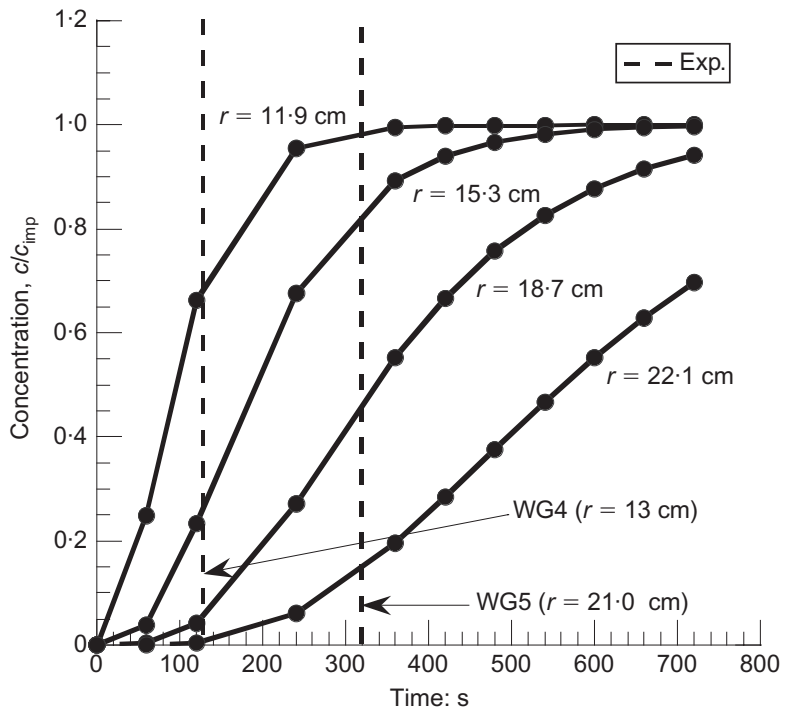

(a)

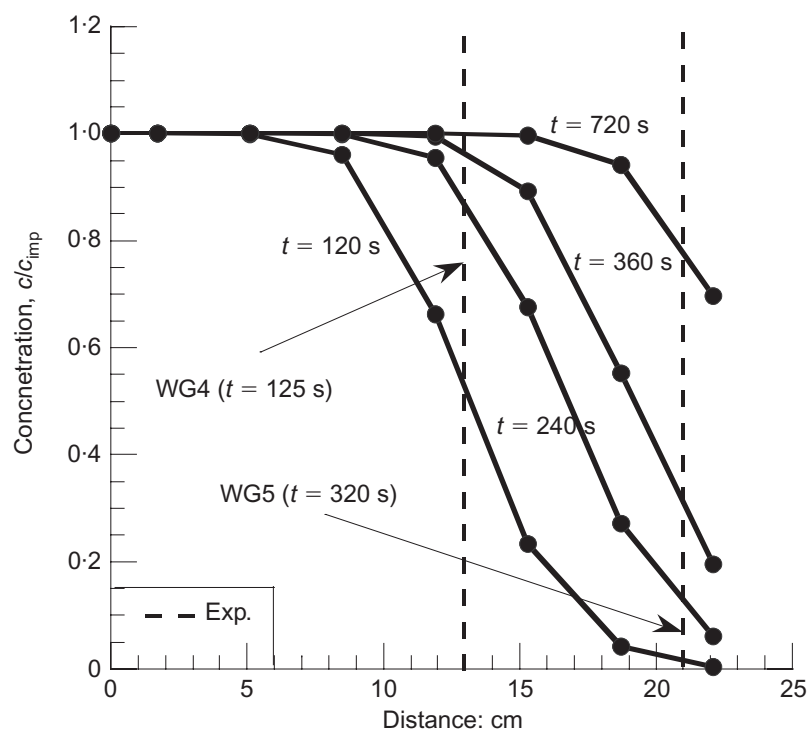

(b)

Fig. 9. Evolution of the concentration profile with (a) time and (b) distance from the injection point

10

$$
\frac{4}{3} \pi R^{3}=\frac{V_{\text {injected }}}{n_{\text {accessible }}}
$$

II

$$
\frac{4}{3} \pi a^{2} b=\frac{V_{\text {injected }}}{n_{\text {accessible }}} \quad \text { with } \quad \frac{a}{b}=\sqrt{\frac{K_{\mathrm{h}}}{K_{\mathrm{v}}}}
$$

where $K_{\mathrm{v}}$ and $K_{\mathrm{h}}$ are the vertical and horizontal permeabilities; $n_{\text {accessible }}$ is the accessible porosity; $V_{\text {injected }}$ is the volume of injected grout; and $a$ and $b$ are respectively the semi-major and semi-minor axes of the ellipse (ellipsoidal model). In calculations $n_{\text {accessible }}$ is equal to the total porosity.

In Table 8 the bulb dimensions for spherical and ellipsoidal propagation models are calculated for two given volumes corresponding to the grout quantity injected in the sand when waveguides 4 and 5 detect an increase of acoustic activity $(t=$

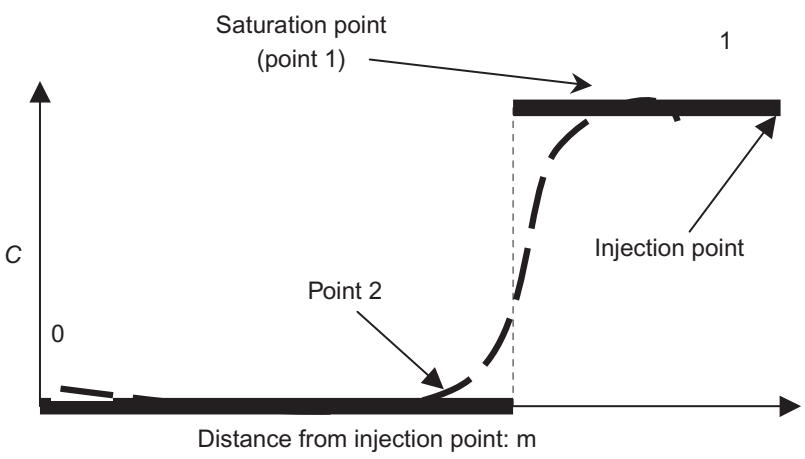

Fig. 10. Schematic representation of concentration evolution

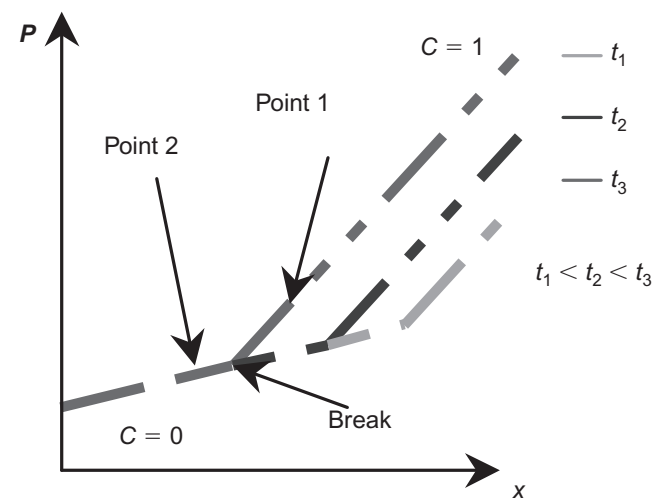

Fig. II. Schematic representation of pressure evolution

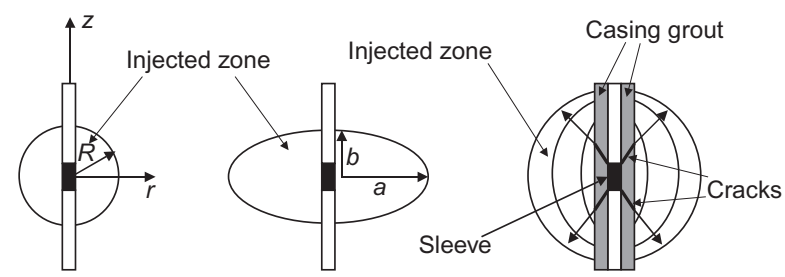

Spherical propagation Ellipsoidal propagation Real grouting case model model

The manchette is assimilated to a point source

(a)

(b)

(c)

Fig. 12. Representation of different grout propagation models

$125 \mathrm{~s}$ and $t=320 \mathrm{~s}$ ). These values are to be compared with those in Fig. 9. Globally, the grout concentration is approximated well by the Athos mathematical model when the distance from the source of injection is not too small. AE detects the grout presence when the numerical concentration starts to increase significantly. Otherwise the model overestimates the grout concentration. This may be because the grout is injected in the soil through cracks in the casing grout, and the injection source cannot be assimilated to a precise point. Indeed, this simplified model does not take into account the dilution of the miscible grout. It provides an estimation of 


\begin{tabular}{|c|c|c|c|c|c|}
\hline \multirow[t]{2}{*}{ Time: $\mathbf{s}$} & \multirow[t]{2}{*}{$V_{\text {injected }}: m^{3}$} & \multirow[t]{2}{*}{ Waveguide postion: $\mathrm{cm}$} & \multirow{2}{*}{$\begin{array}{c}\text { Spherical propagation } \\
\text { model }\end{array}$} & \multicolumn{2}{|c|}{ Ellipsoidal propagation model } \\
\hline & & & & $K_{h} / K_{v}=2$ & $K_{\mathrm{h}} / K_{\mathrm{v}}=4$ \\
\hline 125 & $3.475 \times 10^{-3}$ & $13 \cdot 0$ & $R=13.80 \mathrm{~cm}$ & $\begin{array}{l}a=15.48 \mathrm{~cm} \\
b=10.95 \mathrm{~cm}\end{array}$ & $\begin{array}{l}a=17.38 \mathrm{~cm} \\
b=8.69 \mathrm{~cm}\end{array}$ \\
\hline 320 & $8.896 \times 10^{-3}$ & $21 \cdot 0$ & $R=18.87 \mathrm{~cm}$ & $\begin{array}{l}a=21.18 \mathrm{~cm} \\
b=14.98 \mathrm{~cm}\end{array}$ & $\begin{array}{l}a=23.77 \mathrm{~cm} \\
b=11.89 \mathrm{~cm}\end{array}$ \\
\hline
\end{tabular}

the grouted zone in cases where the concentration is equal to unity in the whole zone.

The results for concentration are validated, and can be used for prediction in other studies, whereas the values obtained by the diffusive model are obviously not in agreement with experience.

In this section it has been shown that both experimental pressures and concentrations are best modelled by Athos software that uses a piston model for grout propagation. The diffusive approach used here does not seem to be appropriate for prediction of this kind of grout transport in such granular media.

\section{CONCLUSIONS}

The goal of this paper is to propose a model to improve the knowledge of the complex technique that is grouting. A comparison was proposed between results obtained from a diffusive and a piston model. Both pressure and concentration were carefully studied. Numerical results were compared with experimental ones, and the following conclusions can be drawn.

(a) The simulation performed with the Athos software seems to fulfil the study goal better.

(b) It proposes a simple model that takes two conservation equations into account, and enables the system to be solved in a relatively short calculation time.

(c) Concentrations are reproduced rather well. The numerical time to full saturation is acceptable, and corresponds to the experimental time. The evolutions are also similar, with the determination of three specific zones: a grout-saturated zone where $c=c_{\max }$, which increases with time; a nongrouted one where $c=0$; and an intermediate zone with a very small thickness.

(d) The numerical values of the pressures correspond to the experimental ones. For the constant pumping rate case, the stationary state in the non-grouted zone and the increase in pressure in the grout-saturated zone are well represented. Nevertheless, some differences may appear when very fine sands are tested.

Athos is also able to simulate grout injection in a threedimensional field, but this was not presented in this paper.

In conclusion, the model used in these simulations proposes a good alternative to the diffusion model. It leads to results that are in accordance with experiment, and therefore seems to reproduce closely the physical phenomena in relation to grout propagation in sands.

\section{ACKNOWLEDGEMENTS}

This work would not have been possible without the help of IFP (Institut Français du Pétrole), which has enabled the authors to extend the use of Athos to grouting problems. The authors would like to thank the FNTP, Vsl-Intrafor, Soletanche Bachy and Euro Physical Acoustics societies for giving access to the experimental results.

\section{REFERENCES}

1. KUTZNER C. Grouting of Rock and Soil. Balkema, Rotterdam, 1996.

2. CAMBefort H. Pression et débit d'injection avec le tube à manchette. Annales de l'Institut Technique du Bâtiment et des Travaux Publics. Série: Sols et Fondations, 1992, 214, No. 500.

3. Chupin 0., SAIYouri N. and Hicher P. Y. Cement grout injection tests in tanks: experiments and modelling. Proceedings of the 5th European Solid Mechanics Conference, Tessalonique University, 2003 (CD-ROM).

4. Chupin 0., SAIYOURI N. and Hicher P. Y. Numerical modelling of cement grout injection in saturated porous media. Proceedings of the 16th ASCE Engineering Mechanics Conference, University of Washington, Seattle, 2003 (CD-ROM).

5. Bouchelaghem F. and Vuluiet L. Mathematical and numerical filtration-advection-dispersion model of miscible grout propagation in saturated porous media. International Journal for Numerical and Analytical Methods in Geomechanics, 2001, 25, No. 12, 1195-1227.

6. Villedary B. Modélisation de la diffusion des coulis de ciment injectés dans les milieux granulaires, Master report. Ecole Centrale de Nantes, 2000, 50 pp.

7. HASSANIZADEH M. and GRAY W. G. General conservation equations for multi-phase systems: 1 . Averaging procedure. Advances in Water Resources, 1979, 2, 131-144.

8. SaAda Z., Canou J., DormieuX L., Dupla J. C. and Maghous S. Modelling of cement suspension flow in granular porous media. International Journal for Numerical and Analytical Methods in Geomechanics, 2005, 29, 691-711.

9. ACKerer P., Younes A. and Mose R. Modeling variable density flow and solute transport in porous medium: 1 . Numerical model and verification. Transport in Porous Media, 1999, 35, 345-373.

10. Amirat Y. and ZiAni A. Global weak solutions for a parabolic system modeling a one-dimensional miscible flow in porous media. Journal of Mathematical Analysis and Application, 1998, 220, No. 2, 697-718.

11. HUtAKORN P. S. and PINDER G. F. Computational Methods in Subsurface Flow. Academic Press, London, 1983.

12. AZZAR G. Modélisation des injections de coulis de bentoniteciment dans les sols. PhD thesis, ENSAM, Bordeaux, 1997. 
13. CHOQUET C. On a nonlinear parabolic system modelling miscible compressible displacement in porous media. Nonlinear Analysis, 2005, 61, No. 1-2, 237-260.

14. Nithiarasu P., SeETHARAmUK N. and Sundarajan T. Finite element modelling of flow, heat and mass transfer in fluidsaturated porous media. Archives of Computer Methods in Engineering, 2002, 9, No. 1, 3-42.

15. BEAR J. Hydraulics of Groundwater. McGraw-Hill, New York, 1979.

16. BEAR J. and BACHMAT Y. Introduction to Modelling of Transport Phenomenon in Porous Media. Kluwer Academic, Dordrecht, Holland, 1991.

17. Simview. Athos, Software Documentation. Beicip-Franlab, Institut Français du Pétrole, 1995.

18. Geotechnical Commission of FNTP. Simulation expérimentale de l'injection monodirectionnelle de coulis de ciment dans les sables. 2001, Contract Report.

19. JASON L., SAIYOURI N. and HICHER P. Y. Study of grout propagation in sands: numerical modelling. Proceedings of the 4th International Conference on Ground Improvement Techniques, Kuala Lumpur, 2002, 2, 437-444.

20. Chupin 0., SAIYouri N. and Hicher P. Y. The effects of filtration on the injection of cement-based grouts in sand columns. Transport in Porous Media, 2007 [DOI: 10·1007/ s11242-007-9146-zy.

21. Euro Physical Acoustic. Suivi par Emission Acoustique de l'Injection de Coulis sur des Colonnes d'Alluvions, Phase2, National Project Report (RGCU), 2002.

22. SAIYOURI N., BOUASKER M. and KHELIDJ A. Gas permeability measurement on injected soils with cement grout. Cement and Concrete Research, 2007, 38, No. 1, 95-103.

23. FENG X. On existence and uniqueness results for a coupled system modelling miscible displacement in porous media. Journal of Mathematical Analysis and Application, 1995, 194, No. 3, 883-910. 